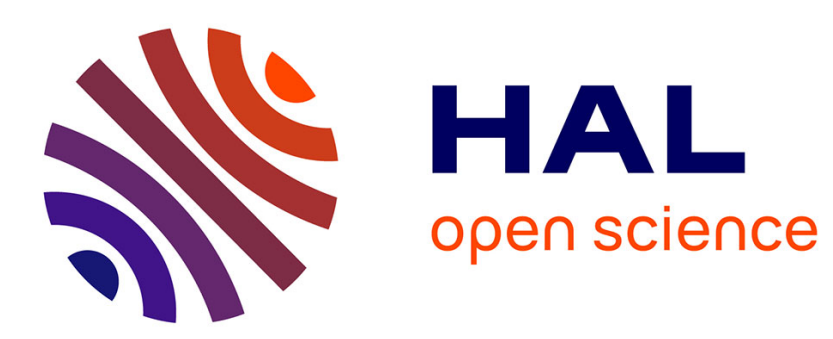

\title{
The political drivers of renewable energies policies
}

Isabelle Cadoret, Fabio Padovano

\section{To cite this version:}

Isabelle Cadoret, Fabio Padovano. The political drivers of renewable energies policies. Energy Economics, 2016, 56, pp.261-269. 10.1016/j.eneco.2016.03.003 . halshs-01290360

\section{HAL Id: halshs-01290360 \\ https://shs.hal.science/halshs-01290360}

Submitted on 18 Mar 2016

HAL is a multi-disciplinary open access archive for the deposit and dissemination of scientific research documents, whether they are published or not. The documents may come from teaching and research institutions in France or abroad, or from public or private research centers.
L'archive ouverte pluridisciplinaire HAL, est destinée au dépôt et à la diffusion de documents scientifiques de niveau recherche, publiés ou non, émanant des établissements d'enseignement et de recherche français ou étrangers, des laboratoires publics ou privés. 


\title{
THE POLITICAL DRIVERS OF RENEWABLE ENERGIES POLICIES ${ }^{1}$
}

\author{
Isabelle Cadoret \\ Fabio Padovano ${ }^{2}$ \\ Centre Condorcet for Political Economy and \\ Centre Condorcet for Political Economy and \\ CREM-CNRS, University of Rennes 1, CREM-CNRS, University of Rennes 1, \\ Rennes, France; \\ Rennes, France; and DPS, University Roma \\ Tre, Italy
}

\begin{abstract}
This paper empirically analyzes how political factors affect the deployment of renewable energy (RE) sources and compares their explanatory power to that of other economic, energy and environmental drivers that have received greater attention in the literature so far. The sample encompasses the EU countries bound to attain the target of $20 \%$ share of gross final energy consumption by 2020. The panel data analysis shows that lobbying by the manufacturing industry negatively affects RE deployment, whereas standard measures of government quality show a positive effect; furthermore left wing parties promote the deployment of RE more than right wing ones.
\end{abstract}

JEL classification codes: Q28, H54, H87, D72, D73, D78

Keywords: renewable energy sources, energy policy, quality of government, lobbying, political ideology

\footnotetext{
${ }^{1}$ Paper presented at the Seminars of Applied Economics of the University of Rennes 1, at the European Public Choice Society Conference in Cambridge, UK, at the Scientific Meeting of the Italian Society of Public Economics. We thank the participants to all these meetings as well as Emma Galli, Niklas Potrafke, Ilaria Petrarca, Yvon Rocaboy and Edilio Valentini for comments on previous versions of this paper. Two anonymous referees have helped us to improve a previous version of the paper. The usual caveat applies.

${ }^{2}$ Corresponding author.Faculté des Sciences Économiques, University of Rennes 1, 7 Place Hoche, 35065 Rennes Frances. E-mail : fabio.padovano@univ-rennes1.fr
} 


\section{THE POLITICAL DRIVERS OF RENEWABLE ENERGIES POLICIES}

\section{Introduction}

This paper has two main goals. The first is to empirically analyze to what extent political factors explain the countries' decisions to deploy renewable energy (RE). The deployment of $\mathrm{RE}$ is a good indicator of countries' commitment in the promotion of environmental friendly energy policies and, as we shall see, one that has received little attention in the scientific literature. The second, closely connected one, is to compare the explanatory power of those political determinants with that of other economic, energy and environmental drivers that have received greater attention in the literature so far, at least in the particular case of RE.

The reasons for interest in this analysis are manifold. To begin with, the attention devoted to the political and institutional drivers fills an analytical lacuna in our understanding of RE deployment. This lacuna is all the more serious, since investing in RE sources is, first and foremost, a political decision. Governments actually finance the deployment of RE in response to multiple political factors. Among them, the pressure of lobbies that demand a greater use of RE sources, like the environmentalists and the green energy industry; the pressure of lobbies instead contrary to such deployment, like the nuclear and the oil based industries; and, last but not least, governments invest in RE provided that it yields a positive rate of return in terms of expected votes.

Furthermore, the deployment of REs is a 'hot' policy issue, as the COP21 conference held in 2015 shows. In the EU; the combined needs of reducing its energy dependency and protecting the quality of the environment have pushed the Commission to set a series of targets that member countries must reach by 2020 (Directive 2009/28/EC); among those, a share of REs in gross final energy consumption of at least $20 \%$. The task is daunting, since considerable differences exist in RE gross final energy consumption among the member countries. Malta, for instance, consumes no RE at all, while in Sweden they represent 43\% of total energy consumption ${ }^{3}$. Such large cross country differences among a group of rather homogeneous and closely integrated economies cast doubts on the validity of models that rely exclusively on economic and environmental determinants. Political factors must also play a role.

To compare the explanatory power of the politico-institutional factors with that of the better studied economic and environmental drivers, our empirical strategy adopts the

\footnotetext{
${ }^{3}$ As shown in Figure 1, section 3.1., in the rest of the EU27 countries the mean value of the RE sources in total energy consumption is $13.76 \%$ for the $2004-2011$ time period, with a variance of 110.24 .
} 
following road-map. First, as virtually all of the theoretical and empirical models that have studied the influence of political drivers on energy and environmental policy have focused on indicators different from the deployment of RE, we begin by illustrating the simple correlations between the countries' RE shares and the main political explanatory variables identified in the literature. In a second step we collapse the politico-institutional variables with the economic, energy and environmental ones into a single empirical model. This allows us to assess the relative explanatory power of the political determinants, but also to investigate whether they exert their influence on REs directly or indirectly, through the mediation of other conditioning phenomena. The influence of a leftist government, for instance, can be expected to be conditional on the cohesion of its parliamentary majority.

The estimates yield several interesting results. First of all, political factors play a significant role in explaining countries' decisions to deploy RE, even when the standard economic, energy and environmental phenomena are explicitly controlled for. The most relevant political drivers are the lobbying power of the manufacturing industry, which effectively retards the deployment of RE, and measures of governance quality, which instead show a positive effect. Left wing parties appear to promote the deployment of RE more than right wing ones.

The rest of the paper is organized as follows. Section 2 presents the main theoretical arguments relating political economy variables with energy policy decisions. Section 3 presents the data and the basic correlations. Section 4 introduces the empirical model and discusses the main results of the estimates. Section 5 concludes.

\section{Literature review}

Both at the theoretical and at the empirical level, political economy analyses of energy and environmental policy decisions have mainly focused on two types of determinants: the quality of government, which also includes the institutional framework where energy and environmental policy decisions are implemented; and the ideology of the incumbent government. Here we will illustrate these two literature strands, to motivate the choice of the independent variables included in our empirical model, described in the next section.

2.1. Quality of governance. The inverted Kutznets curve is the theoretical framework whereby the relationship between the economic performance, the quality of governance and the quality of the environment is usually studied. In poor countries people value material well-being more than environmental amenities; yet, once a country reaches a sufficiently high per capita income, citizens pay greater attention to the environment. Insofar as policies 
respond to people's preferences, we should observe that poor countries tend to sacrifice the environment at the expense of development, while rich countries do the opposite (Arrow et al. 1995).Everything hinges, however, on the extent to which policies (including environmental ones) reflect people's preferences. Corruption, a standard measure of governance quality, reduces the responsiveness of policies to citizens' preferences and should then raise the income level at which environmental protecting policies start to be adopted. Lopez and Mitra (2000) reach this conclusion simulating a model of the environmental consequences of government corruption and rent-seeking. In a similar vein, Fredriksson and Svensson (2003) study both theoretically and empirically the contrasting effects of corruption and political instability on the implementation of environmental policies. They predict that corruption reduces the "stringency" (i.e., the efficiency of implementation) of environmental regulations; yet political instability should offset this effect, as it lowers the rate of return on corrupt practices. They find support for this claim in a cross section analysis on 63 countries.

Some studies in this literature strand associate corruption with lobbying activities. Fredriksson et al. (2004) for instance considers the combined effects of corruption and of industry size - a proxy for lobbying efficiency - on the outcomes of energy policy in the OECD countries. Their theoretical structure builds on the menu auction model and generates quite many predictions disaggregated at the industry level, namely, that (i) greater corruptibility reduces the stringency of energy policy; (ii) higher costs of lobby coordination cause energy policy to become more stringent; (iii) when the effect of energy policy on wages is large (small), the influence of worker coordination costs on the stringency of energy policy is also large (small), whereas the effect on capital owners' coordination costs is small (large). The empirical results, based on sectorial data from 12 OECD countries over the period 19821996, are generally consistent with these theoretical predictions. A number of other empirical studies (Fredriksson, Vollebergh, 2009; Morse 2006; Welsh, 2004) broadly confirm these theoretical predictions using different samples, measures of governance quality and diffusion of lobbies as well as estimating techniques.

2.2. Ideology. Government ideology is another political factor that potentially affects the environmental quality and the stringency of energy policies. Potrafke (2010) investigates the hypothesis (among others) that market oriented and right wing governments have been more active at deregulating product markets, among them, the market for energy. His empirical estimates show that right wing governments do in fact promote deregulation of the energy market. Also the concentration of the government majority seems to positively affect market deregulation, while the institutional constraints, captured by the comprehensive Henisz index, 
appear not to play a major role. Chang and Berdiev (2011) as well as Biressieloglu and Karaibrahimoglu (2012) focus on the effects of government ideology and of other political factors on the energy market alone. Their results confirm that left wing governments favor regulation in the energy sector, with the fragmentation of government again playing a partly offsetting role. More stringent institutional constraints seem to favor the deregulation of the sector. On the other hand, market-oriented, right wing governments endorse energy deregulation, although the link between environmental policy and government ideology in this case appears less evident than for left wing governments. Both studies look at government ideology only, disregarding other political dimensions that may have an impact on energy policy decisions. That is likely to prove a serious neglect, as Neumayer (2003), for instance, makes the interesting point that left wing governments may find themselves in an ambivalent position vis à vis the protection of the environment. That because policy decisions aimed at protecting the environment can be costly in terms of employment levels. Employment concerns may be particularly influential in policy decisions in countries that adopt corporatist governance methods. In such a case a conflict arises in the political objectives of left wing parties when they run the government. Neumayer's (2003) empirical analysis indeed confirms such ambivalence.

To sum up, all these studies concur in pointing out that various indicators of the quality of governance, of the pervasiveness of interest groups, of the type of institutional system in place, as well as of the ideology of governments are all potentially relevant factors in shaping environmental and energy policies - even though none of these studies specifically refers to RE. At the same time, all these studies share three drawbacks. First, they insist on a single type of political economy determinants, i.e., either the quality of governance or political ideology. Second, none of them compares the relative importance of the political drivers of RE deployment with alternative types of conditioning factors, like economic, energy and environmental indicators. Third, although some of these studies exploit panel data, the large majority of them fails to explore the dynamic properties of the estimated relationships, treating them to be either contemporaneous or equilibrium ones. ${ }^{4}$ We try to overcome these shortcomings by a) considering a more comprehensive set of political determinants; b)

\footnotetext{
${ }^{4}$ The only possible exceptions are Marques et al. (2010) and Potrafke (2010). They first use a FEVD model to distinguish between time varying and time invariant covariates. As we shall see in the appendix, this estimator is subject to critiques. Potrafke (2010), instead adopts a least squares dummy variable estimator for dynamic panel data, where the dependent variable is lagged and economic variables enter as growth rates. He limits the analysis to a small set of covariates, however, and does not consider the significance of more than one lag.
} 
comparing the explanatory power of the political drivers with that of the standard economic, energy and environmental factors; c) providing a thorough examination of the dynamic properties of the estimated relationships, checking for their stochastic properties, the significance of different lag structures, trends and time dummies.

\section{Data, correlations and model specification}

3.1. The dataset. We perform our empirical analysis on data about the share of RE in gross energy consumption in a sample of 26 EU countries over the period 2004-2011. The time series of our panel begins in 2004 because Eurostat, our data source for the dependent variable, started to collect coherent data only then; it ends in 2011, the last year for which DPI, the Database of Political Institutions, provides data about political and institutional variables. Within the countries that constitute the cross section dimension of the panel there are 21 OECD countries, namely the EU15 countries (Austria, Belgium, Denmark, Finland, France, Germany, Greece, Ireland, Italy, Luxembourg, the Netherlands, Portugal, Spain, Sweden and the UK) plus the Czech Republic, Estonia, Hungary, Poland, Slovakia and Slovenia. We also consider five non OECD countries that are closely integrated with the OECD group, namely Bulgaria, Cyprus, Romania, Latvia and Lithuania. The sample excludes Malta because the share of RE in gross energy consumption is nihil over the entire period.

3.2. The variables. We select the share of RE in gross final energy consumption as the endogenous variable because it is the closest proxy to the indicator actually referred to in Directive 2009/28/EC. As such, the regressand measures the stringency of the environmental policies of each country ${ }^{5}$.

[Figure 1 about here]

In line with the literature we categorize the explanatory variables in three vectors: 1) the political economy variables $\boldsymbol{W}$, the focus of our analysis; 2) the economic variables $\boldsymbol{X}$; 3) the energy and environmental variables $\boldsymbol{Z}$. Among the political economy variables $\boldsymbol{W}$ we consider the quality of governance, the influence of lobbies, government ideology, as well as the institutional framework where RE deployment decisions are taken. The theoretical literature

\footnotetext{
${ }^{5}$ This is apparently be the same variable considered by Biressieloglu and Karaibrahimoglu (2012). We, however, use only the official Eurostat statistics, the very same that is in the Directive 2009/28/EC. Biressieloglu and Karaibrahimoglu (2012, p. 32) instead merge these data with national statistics to extend time series. Once we tried the same procedure, we noticed 'jumps' in the series that reduce the reliability of the estimates. So we decided to stick to the data that politicians actually observe, i.e., the official Eurostat ones. Furthermore, Biressieloglu and Karaibrahimoglu (2012) examine only government ideology among the political factors, and have a much smaller set of economic, environmental and energy controls.
} 
suggests the following correlations: a higher quality of governance, proxied by lower levels of corruption, should result in more stringent energy and environmental policies, hence in a higher share of RE. To check the robustness of the results, we use two alternative indicators of governance quality: the Corruption Perception Index (CPI), which measures the perceived levels of public sector corruption, from Transparency International. The scale is $[0,10]$, where higher scores mean lower corruption in the broadest possible sense; and the Control of Corruption Index from the World Bank's World Governance Indicators (WBGI_CCI), whose scale is $[-2.5,2.5]$, normally distributed, with a zero mean and a standard deviation of one. The CCI measures corruption perceptions in a narrower sense, since in this case corruption is defined as the exercise of public power for private gain. Higher values again indicate a better control of corrupt practices ${ }^{6}$. Partly because our sample has a limited time dimension, partly because the EU countries feature fairly stable governance systems, the variances within of these indicators are quite limited. We have therefore taken the average values of both the CPI and the WBGI_CCI over time for each country and have considered these measures as country specific characteristics. This also avoids problems of comparison over time that may plague the CPI index.

As for government ideology, left wing governments should prefer more market regulation, also in the domain of environmental policy (Chang and Berdiev, 2011; Biressieloglu and Karaibrahimoglu, 2012); yet, according to Neumayer (2003), tougher environmental controls might negatively affect employment levels, thus creating a conflict among two typical concerns of left wing parties. The evaluation of the overall sign of the correlation is left to the empirical analysis. Our measure of ideology comes from the DPI and consists of a dummy, LEFT, which discriminates between governments supported by a left wing majority, and those that express a right wing or a center ideology ${ }^{7}$. The literature points out that the influence of political ideology on environmental policy decisions can be conditioned by the cohesion of the government majority and by the institutional framework in which the

\footnotetext{
${ }^{6}$ We have also checked another indicator, The ICRG index of the quality of government, which assesses the diffusion of corruption within the political system. The scale is $[0,1]$, where higher values also indicate a better quality of governance. As the results were basically in line with those obtained with the other two indicators, we have omitted them from the main text.

7 The DPI classifies governments as "right wing" when they are supported by parties defined as conservative, Christian democratic, or right wing; as "left wing" when they are supported by parties defined as communist, socialist, social democratic, or left wing; and as center, when the supporting parties advocate strengthening private enterprise in a social-liberal context. As there are very few center governments in our sample, we adopt a more parsimonious specification of the ideology variable and join the center and right wing governments into a single group. The results do not change qualitatively. Incidentally, green and environmentalist parties are considered as left wing by the DPI.
} 
government operates. First, more cohese left wing governments are better able to adopt (and stick to) long run policy decisions, such as RE deployment. Incidentally, more cohese governments may also be more resilient to the influence of lobbies. To capture these effects we have interacted the government ideology dummy with the concentration of the governing coalition, measured by the standard Herfindhal index, HERF, again from DPI. The index ranges between 0 and 1, where 1 denotes single party governments, i.e., the highest possible concentration of the ruling coalition. Second, we have also verified whether the type of government system (parliamentarian vs. presidential) might influence RE deployment, through the different decision making costs that the two institutional frameworks engender. As the effects of the institutional framework on RE deployment have never been explored, no theoretical prior exists about this point. Standard political economy theory, however, maintains that presidential systems, where the government is directly elected in a national constituency, should be better able to implement policies of national scope (Persson and Tabellini, 2001), such as the deployment of RE. To check whether it is the case, we introduce a dummy PARLIAMENTARY, also from DPI. Finally, we examine also the effects of lobbying activities on RE end use. So far, the empirical literature has considered only the lobbying activities of capital owners in the energy industry, usually proxied by the value added of the energy industry as a percentage of GDP (Fredriksson and Vollebergh, 2009; Marques et al., 2010; Marques and Fuinhas, 2011). Higher ratios were associated with higher penetration by the energy industry lobby, which should decrease the stringency of environmental and energy policies. Yet theory (Fredriksson et al., 2004) has argued that the effects of lobbying on environmental policy decisions is a far more complex phenomenon, since also the relative size of the energy industry and the relative lobbying efficiency of workers and capital owners should play a role. No data are available for these theoretical variables, yet we try to adhere as much as possible to the logic of the model by examining the value added of the manufactory sector (VA_MAN), normalized by total GDP. This variable proxies the lobbying strength of the industrial sector most prone to resisting the deployment of RE because of the higher costs that RE engender ${ }^{8}$.

\footnotetext{
${ }^{8}$ In order to obtain a broader picture of the influence of lobbies, we have also considered the value added of the total industry (VA_IND) and of the agricultural sectors (VA_AGR), normalized by total GDP, but they never turned out statistically significant. The same applies when we have introduced the value added of the energy industry and a dummy that marks the presence of state owned enterprises in the energy sector.
} 
Vector $\boldsymbol{X}$ comprises the standard economic variables considered in the literature, namely, the level of GDP per capita (GDP) and its growth rate (GDP_GROWTH), from PWT 8.1 ${ }^{9}$. The expected sign on this covariate is a typical Slutsky equation issue: through an income effect, a higher per capita GDP should stimulate energy consumption, including that produced through RE. On the other hand, peaks of demand that are endemic to energy consumption may trigger the substitution of RE-based energy, which is still erratic and difficult to stock, with other sources (Marques et al., 2010). Which of the two effects dominates determines the sign of the coefficient on per capita GDP. Positive past growth rates of GDP, on the other hand, indicate that more resources have been generated which could be invested in RE; hence the expected sign on lagged GDP_GROWTH is positive.

Finally, vector $\boldsymbol{Z}$ captures the effects of the energy and the environmental variables that have been usually considered in the literature. The first argument of $\mathbf{Z}$ is the real price of energy end use (PRICE) from IEA statistics. As for GDP per capita, we test different lags for this variable. In a contemporaneous setting, a price increase should depress energy demand, including RE. With time, however, higher energy prices should promote policy choices aimed at reducing energy intensity and dependency; moreover, higher prices may make RE more economically viable, thereby encouraging investments in RE. We also consider the energy dependency ratio (DEP_ENERGY) and a measure of the environmental degradation, namely (CO2_ELEC). Energy dependency indicates to what extent a country relies upon imports to meet its energy requirements ${ }^{10}$. As for environmental degradation, in line with Marques et al. (2010) and Marques and Fuinhas (2011), we use CO2 emissions from electricity and heat production (as a percentage of total final combustion) from the World Bank. Both energy dependency and CO2 emissions should push the EU countries to promote the development of RE. Finally, we consider some (time invariant) environmental policy controls. The first captures the commitment of each EU country to the target share of RE in gross final energy consumption for 2020, set by the directive 2009/28/EC. This variable, called TARGET, is the share of RE in gross final energy consumption assigned to the country by the Commission. Its expected sign is positive. The second control identifies to the policy approach that each EU country has adopted to achieve its target. To this end we have introduced the covariate

\footnotetext{
${ }^{9}$ Specifically, GDP per capita is expressed in PPP converted (Chain Series) values, at 2005 constant prices.

${ }^{10}$ Following Eurostat, this indicator is calculated as the net imports of energy divided by the sum of gross inland energy consumption plus bunkers.
} 
environmental taxes (ENV_TAX), which refers to the percentage of total revenues represented by environmental taxes, according to the classification by Eurostat. To the extent that such revenues are actually earmarked for environmental purposes, such as the deployment of RE, the expected sign is positive. ${ }^{11}$

3.3. Simple correlations and descriptive statistics. The descriptive statistics of the dataset are presented in Table 1, while their standard errors are reported in Table 2. Several points are noteworthy, beginning with the large differences that exist among the countries in the share of RE in gross final energy consumption, illustrated in Figure 1.

[Tables 1 and 2 about here]

Since this is the first study to consider the influence of political drivers on RE deployment, we make a first check of the applicability of political models developed for other of energy and environmental policies to the case of RE by illustrating a set of simple correlations. Beginning with the influence of lobbying, the correlation between RE and the value added of the manufacturing sector, reported in Figure 2, is far from being clear cut ${ }^{12}$. Nor for the quality of governance, in Figure 3 proxied by Transparency International's perceived corruption, an evident correlation emerges. Finally, Table 3 looks at the relationship between government ideology and RE deployment. When we consider the overall share of RE in gross energy consumption, we see that countries with a right wing government slightly edge over those with a left wing one. This result changes, however, when we disaggregate the sample between countries that belong to the EU15 group and those that do not (mainly the former eastern European ones). In the EU15 group left wing governments appear more engaged in the deployment of RE, as the literature predicts (Biressieloglu and Karaibrahimoglu, 2012); Spain and Portugal are two cases in point. In the non EU15 countries, however, right wing governments appear to promote RE much more than left wing ones, with Estonia and the Czech Republic as prominent examples. Overall, correlations and descriptive statistics can go only so far in analyzing such a complex phenomenon as the

${ }^{11}$ We have also considered two alternative instruments, to verify whether each country relies more on a market-based approach to pursue environmental goals, like tradable green certificates TGC, or on a more interventionist approach, that uses feed-in tariffs FIT as the principal instruments (Nielsen and Jeppesen, 2003; Fouquet and Johanson, 2008; Schallenberg-Rodrigueza and Haasb, 2012). The covariate that discriminates between the two approaches, however, has never turned out significant, when considered alongside environmental taxes. results.

\footnotetext{
${ }^{12}$ The correlation with the value added of total industry and of the agricultural sector yield quite similar
} 
determinants of RE deployment; a more comprehensive model, which includes all the possible conditioning factors together, is needed.

[Figures 1-3 and table 3 about here]

3.4. Model specification and estimation procedures. Equation (1) expresses our model regression. To allow the interpretation of the estimated coefficients (when possible) as elasticities, we express the dependent variable in natural logarithms, (logRE). All arguments of vectors $\boldsymbol{X}, \boldsymbol{Z}$ and $\boldsymbol{W}$ are also expressed in logs, with the exception of the variables in shares and growth rates. The equation is estimated with country specific effects $\alpha_{i}$

$$
\log R E_{i t}=\alpha_{i}+\delta t+\beta \boldsymbol{X}_{i t}+\gamma_{1} \boldsymbol{Z}_{i t}+\gamma_{2} \boldsymbol{W}_{i t}+\varepsilon_{i t}
$$

The model specification and the choice of the estimating technique depend on two issues of dynamics. The first issue is the stationarity - or not - of the dependent variable. To verify this we have performed a series of Levin-Lin-Chu panel unit-root tests on all the time varying continuous variables considered in equation (1). Table 4 reports the results. In all cases, the tests allow us to reject the null that the panels contain a unit root against the alternative hypothesis that they are trend stationary. This result was expected because of the relatively short time dimension of the panel. We therefore insert a trend $t$ in the specification of the model, like in Fredriksson and Vollebergh $(2009)^{13}$. The second issue hinges on the heterogeneous dynamics of the estimated relationships. Some economic variables, like the price of energy, may have both short term effects - on the consumption of RE - and long term ones - on investments in RE deployment. Other time variant variables, instead, like the proxies for governance quality and some institutional factors, should produce only delayed effects, either directly or through the energy and the environmental policies adopted. To disentangle the short from the long run effects, we introduce the variables referring to economic activity and to energy prices both in simultaneous values and with lags, while the other time variant variables are all specified with lags. Furthermore, we adopt the two step estimating technique of Greene (2011) by applying first a LSDV estimator that excludes the time invariant variables, and then by regressing the vector of the fixed effects on the time invariant/rarely changing variables via an OLS method with Eicker-White robust covariance matrix. Finally, the variable TARGET poses concerns of potential endogeneity, at least for two reasons: first, it is highly correlated with the dependent variable, the share of RE in gross final energy consumption (coefficient of correlation $r=0.95$ ); second, it is conceivable that the EU commission fixed a target for each country on the basis of the characteristics of its energy

\footnotetext{
${ }^{13}$ To verify the robustness of the result we have estimates the same model using year dummies too, but they never proved statistically significant.
} 
sector. We have treated this potential problem specifically, by re estimating equation 1 with the Hausman-Taylor estimator, which is explicitly a GLS-IV estimator that generates instruments for the covariates. The results, available upon request, do not change qualitatively, suggesting that endogeneity should not be an issue. Other independent variables, on the other hand, are not likely suspects of endogeneity, either because they enter with lags, or because, like the indicators of corruption, it is really difficult to imagine how a larger share of RE in gross final energy consumption could affect the country's perceived corruption.

\section{Estimation results}

The results of the estimates of equation (1) are presented in Tables5a-5b. Table 5a illustrates the results of stage one, which applies a LSDV estimator to the "time variant" variables; table $5 b$ reports the results of the OLS regression of the fixed effects vector on the time invariant/rarely changing variables based on the best fitting estimates. The second stage models of the LSDV estimates use the most parsimonious first stage specification, i.e., the one including just the variables and lags found to be statistically significant. All specifications include country fixed effects.

4.1. The role of economic factors. The consideration of the variables related to GDP yields the first innovative results. The literature survey indicates that there is no conclusive empirical evidence of an impact of economic variables on the deployment of RE in electricity production; this is a rather odd result, as it is quite difficult to conceive that variations in economic activity do not have any impact on RE. We, however, find a pattern of statistically significant, albeit partially contrasting effects of economic variables on the share of RE in gross consumption, a negative one from the per capita GDP and its contemporaneous growth, while a positive one on lagged GDP growth. The lack of statistical evidence in the previous studies might thus be explained by a misspecification of the complex dynamics of the relationship between RE deployment and the variables that meter the state of the economy. To uncover this dynamics we have followed the statistical significance tests, which indicated to include the GDP per capita with one lag and its rate of growth in contemporaneous values and with one lag. The results thus obtained suggest that when economic activity increases, the greater energy consumption that the increased production requires is not immediately met by RE, but rather by other, more elastic energy sources that can be more easily stocked and/or imported, like fossil based ones. Hence the ratio of RE consumption on gross energy consumption decreases. On the other hand, this greater energy demand stimulates greater 
investment in RE production, which explains why the lagged growth rate of GDP per capita shows instead a significant and positive effect on the share of RE. This effect is however quantitatively similar to the negative one found on contemporaneous growth, to the point that the two apparently cancel out. A possible explanation for the neutrality of economic growth on RE deployment might be that the TARGET variable actually captures the countries' investment in RE (Table 5b). This would also imply that, without the stimulus dictated by the EU, market forces would not be sufficient - and would not find economically viable - to increase the share of RE in gross energy consumption - a classical example of market failure. Furthermore, the linear trend, introduced as in Fredriksson and Vollebergh (2009) to proxy the effects of technological progress on RE consumption, has always the expected positive coefficient and it is statistically significant in all specifications, with values around 0.06 . The presence of the variable TARGET among the rarely changing ones excludes the possibility that the linear trend captures the country's progressive approaching to the target set by the EU Commission.

This rather complex but stable pattern of results demonstrates the importance of investigating the dynamics of the relationship between economic state variables and $\mathrm{RE}$ deployment.

4.2. The impact of energetic and environmental factors. Among the energy and environmental factors $Z$ we focus first on energy prices. We consider the energy end-use price, which is linked to the prices of fossil-based fuels and provides the basis for the price for energy consumers. We verify both the contemporaneous effects of energy prices on RE energy consumption and, with delays linked to investment, on energy production as well. For instance, the use of RE to product electricity becomes more competitive when the prices of fossil-based fuels are higher; an increase of energy prices should then favor the substitution from fossil-based fuels towards RE with some delay.

The results of the estimates show that, on the one hand, energy prices have a significant and positive effect on the share of RE in gross consumption with a two period delay. The price elasticity approximates 0.9 , in all specifications. An increase of the energy prices makes RE more economically viable and promotes its deployment with a delay of two years. As for the other energy and environmental factors considered, four more results are worth noting. First, a $1 \%$ increase of the energy dependency ratio will induce a $0.6 \%$ simultaneous increase of the share of RE, in all specifications. This result is especially interesting in light of the EU energy policy aimed at reducing the energy dependency ratio of the member countries, at increasing their energy efficiency and at reducing the imports of fossil-based fuels. Second, 
environmental degradation too triggers a substitution of standard energy sources by RE ones, as the (expected) positive coefficient on the third lag of the CO2_ELEC variable confirms. Environmental taxes are neutral with respect to the deployment of RE, as the lack of statistical significance of the estimated coefficient on ENV_TAX shows. A political economy explanation is that their revenues do not finance this particular form of environmental protection, but they are likely used for general budget purposes. Finally, and not surprisingly, countries with a higher target for RE deployment in 2020 are also characterized by a higher share of RE than countries with lower targets (table 5b).

[Tables 5a and5b about here]

4.3. Political economy variables. Finally, vector $W$ features the political economy covariates, the principal interest of our analysis. Starting from the lobbying variables, the pressure from the manufactural sector provides a noticeable resistance to the deployment of $\mathrm{RE}$, with a 3 years delay ${ }^{14}$. Being quite energy dependent, both within the industrial sector and the economy at large, manufacturers tend to resist the increase of energy costs that RE engender. Another possible interpretation is that the manufactural sector is opposed to environmental regulations in general, of which RE deployment is an important part.

Coming to the ideology of the government majority, we have first investigated whether EU15 countries and non EU 15 ones behave differently in the deployment of RE when they are governed by a left wing majority. The descriptive statistics of table 3 suggested that this appeared to be the case, conditional on the imposition of the ceteris paribus condition that only the regression analysis allows. Model 1 suggests that, once this condition is considered, left wing governments of both EU15 and non EU 15 countries promote the deployment of RE more than their right wing counterparts. This effect appears with a three year delay - a fairly standard policy implementation lag. The differences among these two groups of countries are however negligible: the Fisher test of equality of the coefficients on the LEFTEU15 and the LEFT $^{\times}$non EU15 regressors rejected the null that they are statistically significantly different. In model 2 we have therefore joined the two interactive variables into a single dummy LEFT, which confirms that, when left wing governments are in the government, the share of RE in gross final energy consumption is $6 \%$ higher than when the government is supported by a right wing majority, all other things being equal. The positive coefficient on the LEFT

\footnotetext{
${ }^{14}$ We have also tried to consider only the energy industry, but neither the KLEMS database, nor OECD data provide a sufficient coverage for our sample. Furthermore, we have considered also the share of value added of the agricultural sector and of the overall industrial sector, without ever finding significant effects. The results with the alternative lobbying indicators are available upon request.
} 
covariate indicates that the contrasting concerns between environmental protection and maximization of employment that Neumayer (2003, 2004) refers to is either not an issue in our sample or it has been solved in favor of RE deployment. Finally, in model 3 we have interacted the dummy LEFT with a the Herfindhal metrics of the concentration of the government majority, to verify whether this acts as conditioning phenomena, but this never appears to be the case.

The governance quality indicator - the Corruption Perception Index from Transparency International-is among the covariates that are time invariant or are characterized by low time variability. The estimates overall confirm the positive effect of the quality of governance on the deployment of RE, as it shows a significant and positive correlation with the dependent variable. Model (1) shows that, with respect to such result, there is no difference between EU15 countries and the rest of the sample. To check for robustness we have also re-estimated equation (1) using the World Bank's Control of Corruption Index (Table 5c, model 4); the results are quite similar. Finally, there is no evidence that either parliamentary or presidential regimes make any difference in the way decisions about RE deployment are taken. The dummy PARLIAMENTARY is never statistically significant, neither alone nor when interacted with LEFT governments.

To verify the relative impact (and explanatory power) of the main covariates considered on RE, we have estimated the effect of $1 \%$ changes (or of unitary changes for the noncontinuous variables) on the dependent variable for all the countries included in the sample. The first column to the right of the list of the countries reports the share of RE in gross final energy consumption for each country in the year 2013. The following columns report what this value would have been in the case where each of the variables had a 1\% increase; or if it had changed value for the dummy LEFT; or it had increased by a unit in the score of the CPI variable (i.e., a 1 point improvement in the quality of governance). The estimated values show that the political variables, especially the quality of governance, exert the quantitatively largest impact on gross final consumption of RE. In most countries in the sample, a 1 unit increase in the score of the quality of governance in the years of the sample would have resulted in a share of RE in gross final consumption roughly $10 \%$ larger. The same effect would have been obtained by a $10 \%$ rise in the country's energy dependency, or by a $8 \%$ growth of the price of energy. All in all, political factors are an important driver of RE deployment. 


\section{Conclusion}

The analysis presented in this paper highlights the role played by political factors in the deployment of RE, in the sample of the EU countries engaged to reach a target of $20 \%$ share of gross final energy consumption by 2020. Among the most clear-cut results, we find that the manufactural industry lobbying effectively retards the deployment of RE, whereas standard measures of governance quality show a positive effect. Finally, left wing parties promote the deployment of RE more than right wing ones, regardless of the level of concentration of the governing majority and the institutional framework where decisions about RE deployment are taken. These results are robust to changes in the model specification and to controlling for the standard economic, energy and environmental covariates that have been usually considered in the literature.

Yet, our analysis also clarifies a series of unsettled issues in the literature on the drivers of environmental and energy policy choices. The panel data analysis shows that, while per capita income has a negative impact on RE deployment, economic growth seems to be neutral. This is possibly due to the fact that the countries' engagement to reach the EU target of RE sources in energy consumption is the main stimulus to investing in RE deployment; market forces would not be sufficient. On the other hand, the lack of any significant correlation between environmental tax revenues and RE deployment suggests that governments use such revenues for general purposes rather than for the protection of the environment. All in all, the forces that affect the spread of RE in energy consumption appear to follow complex processes, that deserve further research effort. 
References

Antweiler W., Copeland R.B., and Taylor S. M. (2001). Is free trade good for environment? American Economic Review 91: 877-908.

Arrow K., Bolin B., Costanza R., Dasgupta P., Folke C., Holling C.S., Jansson B-O, Maler K-G, Perrings C., and Pimentel D. (1995). Economic growth, carrying capacity, and the environment. Ecological Economics 15: 91-95.

Beck, T. C., Groff, A., Keefer, P., \& Walsh, P. (2001). New tools in comparative political economy : the database of political intitutions. World Bank Economic Review 15: 165176.

Biresselioglu, M. E. and Karaibrahimoglu, Y. Z. The government ideology and use of renewable energy: Case of Europe. Renewable Energy 47: 29-37

Breush T., Ward M.-B., Nuguyen H.T.M., Kompas T. (2011). On the fixed effects vector decomposition. Political Analysis 19: 123-134

Carley, S. (2009). State renewable energy electricty policies: An empirical evaluation of effectiveness. Energy Policy 37: 3071-3081.

Chang, C., and Berdiev, A. (2011). The political economy of energy regulation in OECD countries. Energy Economics 33: 816-825.

Directive 2009/28/CE du Parlement Européen et du Conseil du 23 avril 2009, Journal officiel de l'Union Européenne, L. 140/30, 5 juin 2009.

Fouquet, D., and Johanson, T. (2008). European renewable energy policy at crossroads focus on electricity support mechanisms. Energy Policy 36: 4079-4092.

Fredriksson, P. (1997). The political economy of pollution taxes in a small open economy. Journal of Environmental Economics and Management 33: 44-58.

Fredriksson, P., and Svensson, J. (2003). Political instability, corruption and policy formation: the case of environmental policy. Journal of Public Economics 87: 1383-1405.

Fredriksson, P., Vollebergh, R., and Dijkgraafb, E. (2004). Corruption and energy efficiency in OECD countries: theory and evidence. Journal of Environmental Economics and Management 47: 207-231.

Fredriksson, P., and Vollebergh, R. (2009). Corruption, federalism, and policy formation in the OECD: the case of energy policy. Public Choice 140: 205-221.

Greene W.H. (2011). Fixed effects vector decomposition, A magical solution to the problem of time-invariant variables in fixed effects models? Political Analysis 19, 135-148

Gregorini, F., and Longoni, E. (2009). Inequality, political systems and public spending. Working Paper Series n. 159. Department of Economics, University of Milano Bicocca.

Grossman, G., and Helpman, E. (1994). Protection for sale. American Economic Review 84: 833-850.

Heston, A., Summers, R., \& Aten, B. (2012). Penn World Table Version 7.1. University of Pennsylvania: Center for International Comparisons of Production, Income and Price. 
Lopez, R., and Mitra, S. (2000). Corruption, pollution, and the Kuznets environment curve. Journal of Environmental Economics and Management 40: 137-150.

Marques, A. C., Fuinhas, J. A., and Manso, J. (2010). Motivations driving renewable energy in European countries. Energy Policy 38: 6877-6885.

Marques, A., and Fuinhas, J. (2011). Drivers promoting renewable energy : A dynamic panel approach. Renewable and Sustainable Energy Reviews15: 1601-1608.

Morse, S. (2006). Is corruption bad for environmental sustainability? A cross-national analysis ? Ecology and Society11: 1-22.

Neumayer, E. (2003). Are left-wing party strength and corporatism good for the environment? Evidence from panel analysis of air pollution in OECD countries. Ecological Economics 45: 203-220.

Neumayer, E. (2004). The environment, left-wing political orientation and ecological economics. Ecological Economics51: 167- 175.

Nielsen, L., and Jeppesenb, T. (2003). Tradable green certificates in selected European countries. Energy Policy 31: 3-14.

Persson, T. and Tabellini, G., (2001). Political Economics: Explaining Economic Policy. Cambridge, MIT Press.

Plümper, T., and Troeger, V. (2007). Efficient estimation of time-invariant and rarely changing variables in finite sample panel analyses with unit fixed effects. Political Analysis 15: 124-39.

Potrafke, N. (2009). Did globalization restrict partisan politics? An empirical evaluation of social expenditures in a panel of OECD countries. Public Choice 140: 105-124.

Potrafke, N. (2010). Does government ideology influence deregulation of product markets? Empirical evidence from OECD countries. Public Choice 143: 135-155.

Schallenberg-Rodrigueza, J., and Haasb, R. (2012). Fixed feed-in tariff versus premium: A review of the current Spanish system. Renewable and Sustainable Energy Reviews 16: 293-305.

Shrimali, G., and Kniefel, J. (2011). Are government policies effective in promoting deployment of renewable electricty resource? Energy Policy39: 4726-4741.

Welsch, H. (2004). Corruption, growth, and the environment: A cross-country analysis. Environmental Development Economics 9: 663-693.

Wong S. L., Xhia W-M., and Chang Y. (2013). Energy consumption and energy R\&D in OECD: Perspectives from oil prices and economic growth. Energy Policy 62: 15811590 . 
Table 1. Variable sources and descriptive statistics

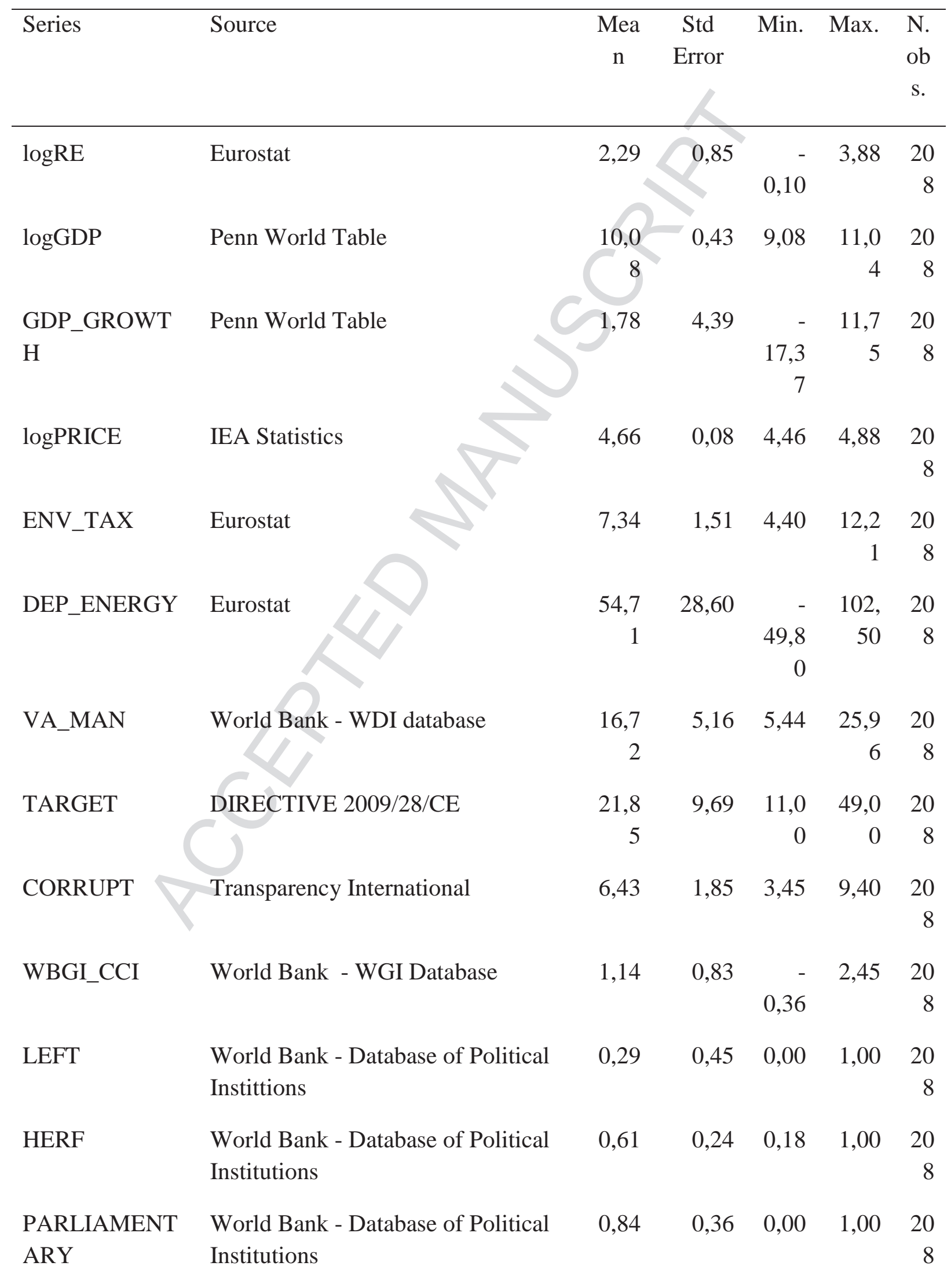


Table 2. Standard errors

\begin{tabular}{llll}
\hline Series & Overall & Between & Within \\
\hline logRE & 0,85 & 0,84 & 0,22 \\
logGDP & 0,43 & 0,43 & 0,05 \\
GDP_GROWTH & 4,39 & 1,58 & 4,11 \\
logPRICE & 0,08 & 0,03 & 0,08 \\
ENV_TAX & 1,51 & 1,41 & 0,61 \\
DEPENERGIE & 28,60 & 28,61 & 5,23 \\
VA_MAN & 5,16 & 5,11 & 1,18 \\
TARGET & 9,69 & - & - \\
CORRUPT & 1,85 & - & - \\
WBGI_CCI & 0,83 & - & - \\
LEFT & 0,45 & 0,31 & 0,33 \\
HERF & 0,24 & 0,24 & 0,084 \\
PARLIAMENTARY & 0,36 & - & - \\
\hline
\end{tabular}


Figure 1. Share of RE in gross energy consumption (\%) mean values 2004-2011

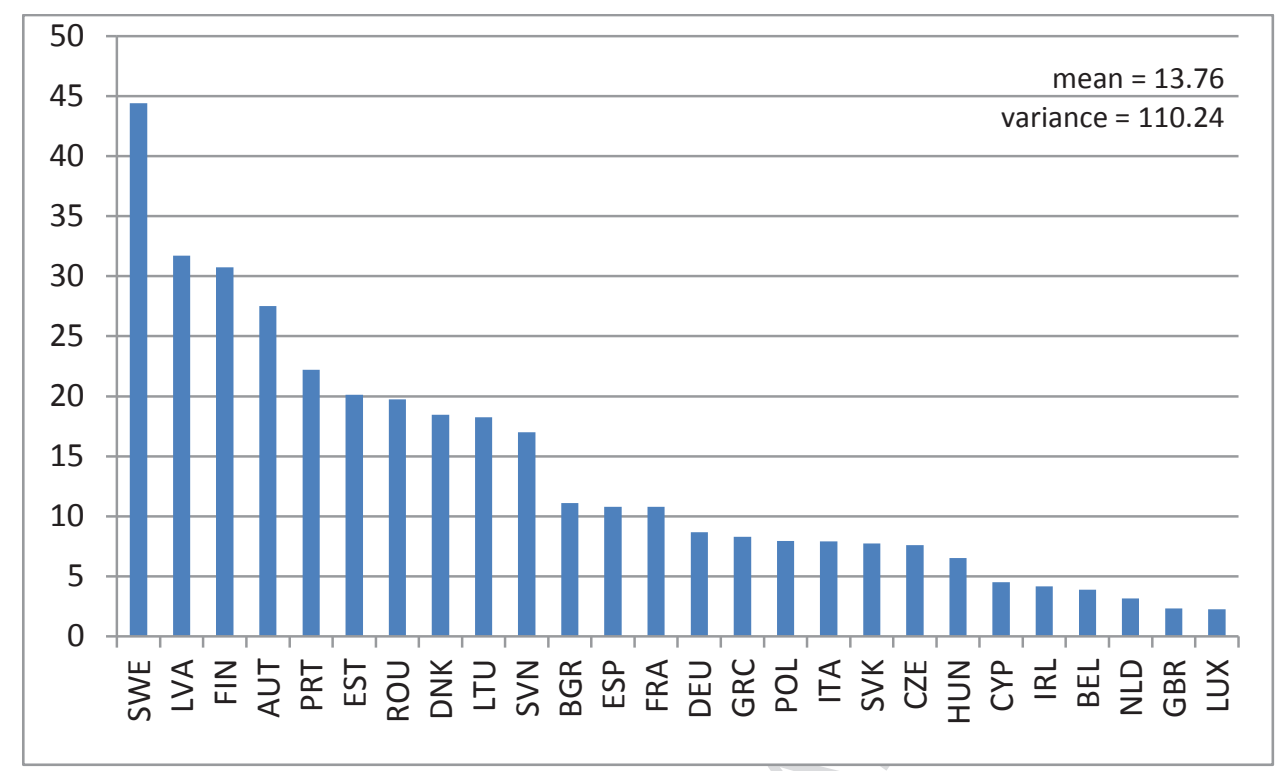

AUT : Austria, BEL : Belgium, BGR : Bulgaria, CYP : Cyprus, CZE : Czech Republic, DNK : Denmark, EST : Estonia, FIN : Finland, FRA : France, DEU : Germany, GRC : Greece, HUN : Hungary, IRL : Ireland, ITA : Italy, LVA : Latvia, LTU : Lithuania, LUX :

Luxembourg, NLD : Netherlands, POL : Poland, PRT : Portugal, ROU : Romania, SVK : Slovakia, SVN : Slovenia, ESP : Spain, SWE : Sweden, GBR : United Kingdom

Source : Eurostat

Figure 2. Lobbying influence

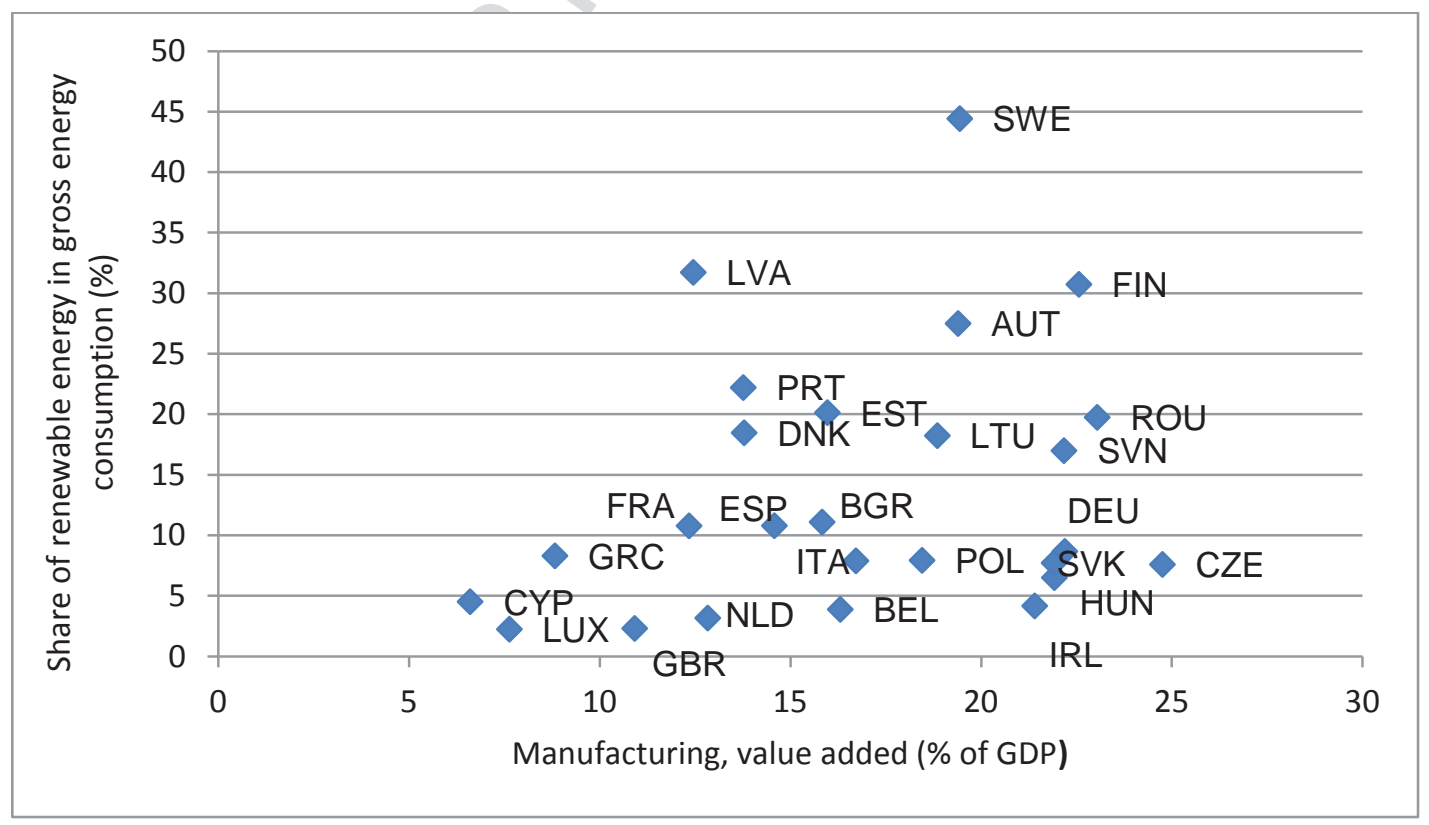

AUT : Austria, BEL : Belgium, BGR : Bulgaria, CYP : Cyprus, CZE : Czech Republic, DNK : Denmark, EST : Estonia, FIN : Finland, FRA : France, DEU : Germany, GRC : Greece, HUN : Hungary, IRL : Ireland, ITA : Italy, LVA : Latvia, LTU : Lithuania, LUX : Luxembourg, NLD : Netherlands, POL : Poland, PRT : Portugal, ROU : Romania, SVK : Slovakia, SVN : Slovenia, ESP : Spain, SWE : Sweden, GBR : United Kingdom

Source : Eurostat and World Bank (WDI database) 
Figure 3. Quality of governance

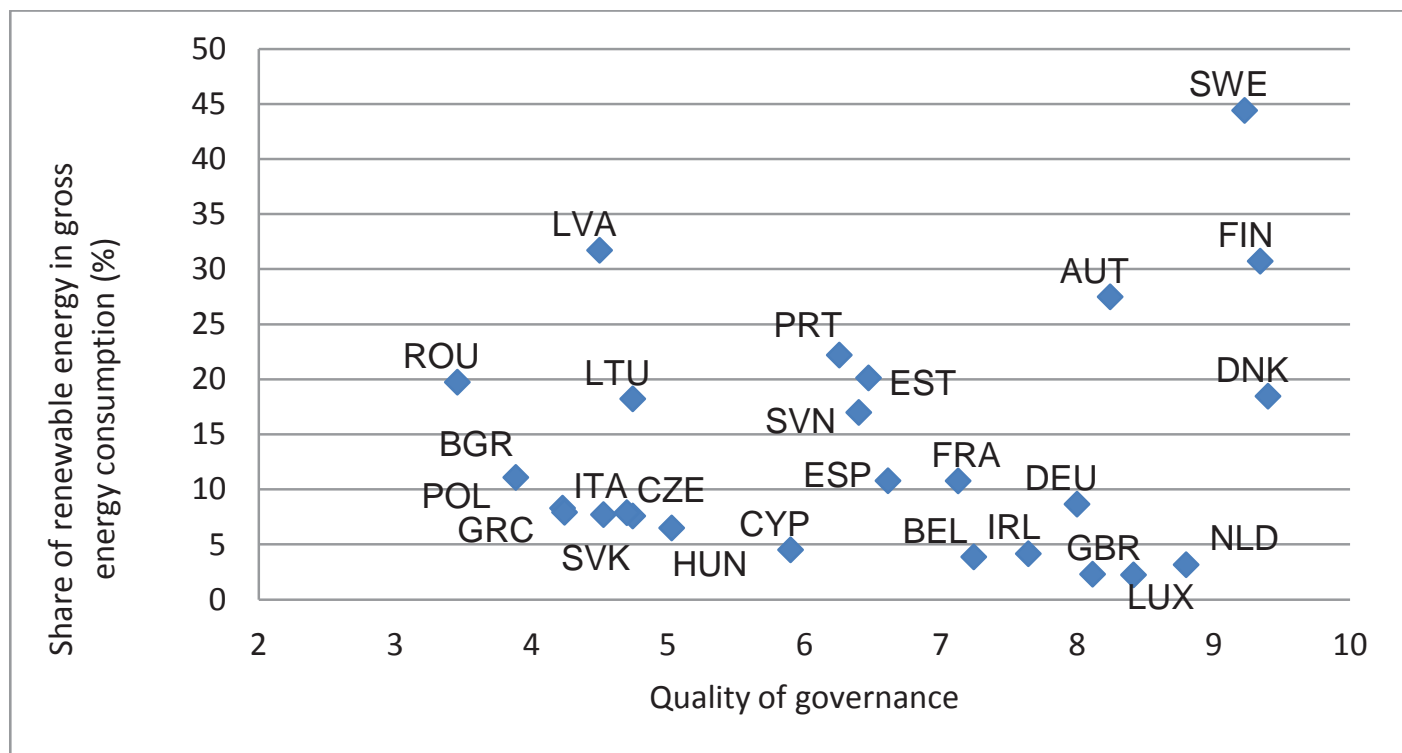

AUT : Austria, BEL : Belgium, BGR : Bulgaria, CYP : Cyprus, CZE : Czech Republic, DNK : Denmark, EST : Estonia, FIN : Finland, FRA : France, DEU : Germany, GRC : Greece, HUN : Hungary, IRL : Ireland, ITA : Italy, LVA : Latvia, LTU : Lithuania, LUX : Luxembourg, NLD : Netherlands, POL : Poland, PRT : Portugal, ROU : Romania, SVK : Slovakia, SVN : Slovenia, ESP : Spain, SWE : Sweden, GBR : United Kingdom

Source : Eurostat and Transparency Agency

Table 3. RE and government ideology

\begin{tabular}{|l|c|c|c|}
\hline & All countries & EU 15 countries & Non EU 15 countries \\
\hline Left $=0$ & 14.1 & 12.82 & 15.7 \\
\hline Left $=1$ & 13.0 & 15.8 & 9.0 \\
\hline
\end{tabular}

Table 4. Test of stationary: Levin-Lin-Chu unit-root test (AIC Criteria)

\begin{tabular}{lll}
\hline Variable & Statistic & p_value \\
\hline log RE (dependent variable) & -8.55 & 0.000 \\
log GDP & -5.01 & 0.000 \\
log PRICE & -13.17 & 0.000 \\
ENV_TAX & -8.73 & 0.000 \\
log DEP_ENERGY & -13.71 & 0.000 \\
VA_MAN & -4.82 & 0.000 \\
CO2_Elec & -9.17 & 0.000 \\
\hline
\end{tabular}


Table 5a: Estimates of Equation (1) Stage 1 Greene

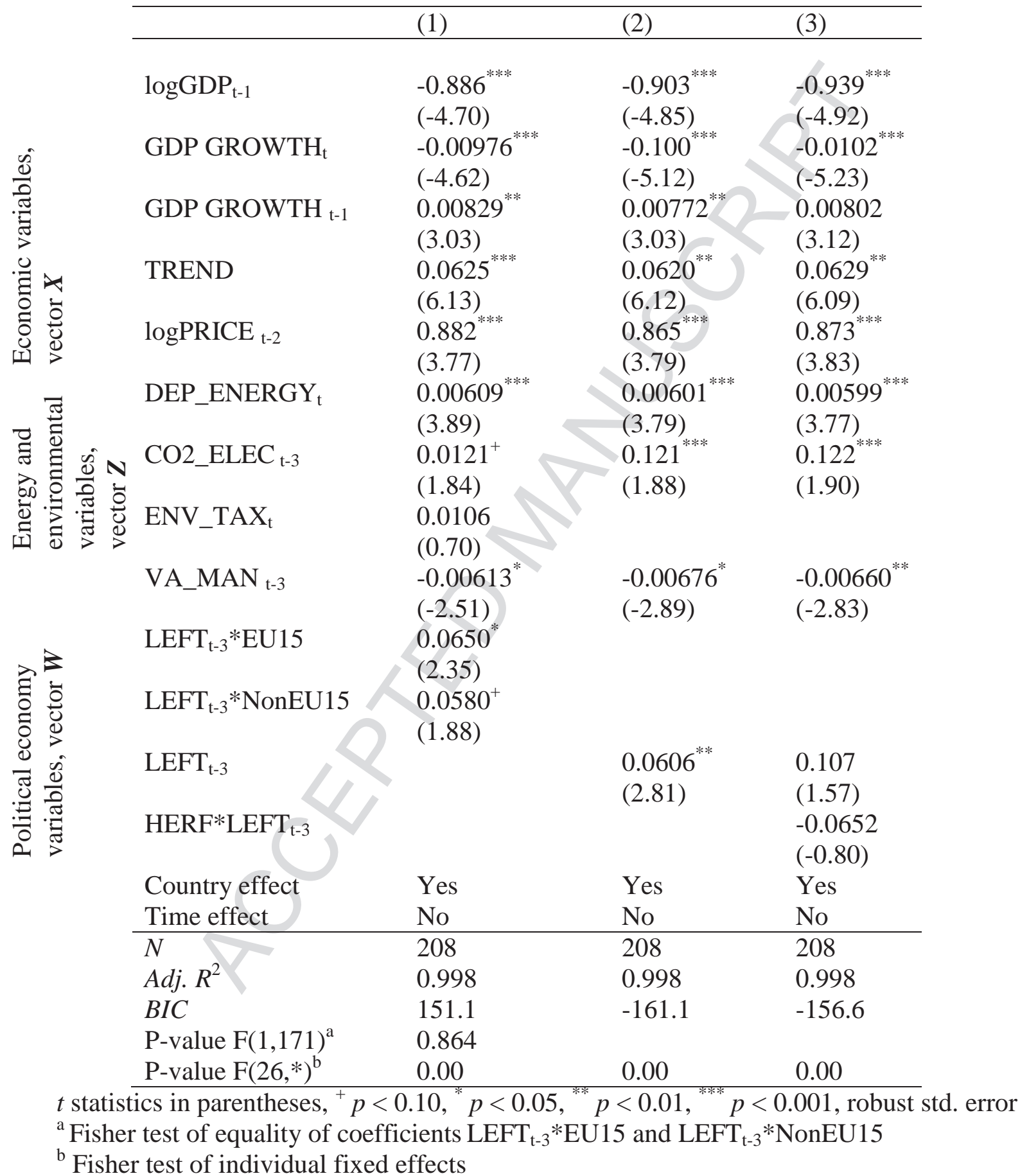


Table 5b: Estimates of Equation (1) Stage 2 Greene

Dependent variable: log of the share of RE in gross final energy consumption

\begin{tabular}{|c|c|c|c|c|}
\hline & & (1) & $(2)$ & (3) \\
\hline \multirow{8}{*}{ 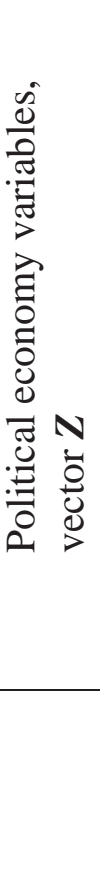 } & EU15 countryt $_{\mathrm{t}}$ & $\begin{array}{l}0.0470 \\
(0.25)\end{array}$ & & $\theta$ \\
\hline & TARGET $_{\mathrm{t}}$ & $\begin{array}{c}0.0750^{* * *} \\
(9.34)\end{array}$ & $\begin{array}{c}0.0741^{* *} \\
(9.47)\end{array}$ & $\begin{array}{c}0.0750^{* * *} \\
(9.71)\end{array}$ \\
\hline & PARLIAMENTARY $_{\mathrm{t}}$ & $\begin{array}{l}0.117 \\
(0.55)\end{array}$ & & \\
\hline & $\mathrm{CPI}_{\mathrm{t}}$ & $\begin{array}{c}0.0672 \\
(1.44)\end{array}$ & $\begin{array}{r}0.0754^{+} \\
(1.85)\end{array}$ & $\begin{array}{c}0.0817^{*} \\
(2.17)\end{array}$ \\
\hline & CONSTANT & $\begin{array}{l}4.193^{* * *} \\
(16.01)\end{array}$ & $\begin{array}{l}4.154^{* * *} \\
(17.58)\end{array}$ & $\begin{array}{l}4.225^{* * *} \\
(21.22)\end{array}$ \\
\hline & $N$ & 26 & 26 & 26 \\
\hline & Adj. $R^{2}$ & 0.842 & 0.850 & 0.852 \\
\hline & $B I C$ & 28.54 & 25.10 & 22.53 \\
\hline
\end{tabular}

$t$ statistics in parentheses

${ }^{+} p<0.10,{ }^{*} p<0.05,{ }^{* *} p<0.01, \stackrel{* * *}{\circ} p<0.001$

Table 5c. Estimates of Equation (1) Stage 2 Greene. Robustness checks

\begin{tabular}{|c|c|c|c|}
\hline & \multicolumn{3}{|c|}{ Dependent variable: log of the share of RE in gross final energy consumption } \\
\hline & & (4) & (5) \\
\hline \multirow{5}{*}{ 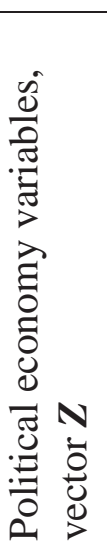 } & TARGET $_{\mathrm{t}}$ & $0.0750^{* * *}$ & $0.0761^{* * *}$ \\
\hline & & $(9.71)$ & $(10.22)$ \\
\hline & $\mathrm{CPI}_{\mathrm{t}}$ & $\begin{array}{c}0.0817^{*} \\
(2.17)\end{array}$ & \\
\hline & WBGI_CCI & & $\begin{array}{l}0.175^{+} \\
(2.06)\end{array}$ \\
\hline & CONSTANT & $\begin{array}{l}4.225^{* * *} \\
(21.22)\end{array}$ & $\begin{array}{l}4.589^{* * *} \\
(30.97)\end{array}$ \\
\hline & $N$ & 26 & 26 \\
\hline & Adj. $R^{2}$ & 0.852 & 0.846 \\
\hline & $B I C$ & 22.72 & 23.60 \\
\hline
\end{tabular}

$t$ statistics in parentheses

${ }^{+} p<0.10,{ }^{*} p<0.05,{ }^{* *} p<0.01,{ }^{* * *} p<0.001$ 
Table 6. Quantitative impacts of changes in the explanatory variables on the share of RE in gross energy final consumption, disaggregated by country

\begin{tabular}{|c|c|c|c|c|c|c|c|c|c|}
\hline$\Delta$ considered & $\begin{array}{l}\text { RE } \\
\text { in } \\
201 \\
3\end{array}$ & $\begin{array}{c}\log G D \\
P\end{array}$ & $\begin{array}{c}\text { GDP } \\
\text { GROWT } \\
\text { H } \\
+1 \%\end{array}$ & $\begin{array}{c}\log P R I C \\
E\end{array}$ & $\begin{array}{c}\text { DEP_ENER } \\
\text { GY }\end{array}$ & $\begin{array}{c}\mathrm{CO} \\
2\end{array}$ & $\underset{\mathrm{N}}{\text { VA_MA }}$ & $\begin{array}{c}\text { Change in } \\
\text { dummy } \\
\text { variable }\end{array}$ & $\begin{array}{c}+1 \text { point } \\
\text { in }[0-10] \\
\text { scale }\end{array}$ \\
\hline & 32 & & & & & & & & \\
\hline Austria & 6 & 32,3 & 32,5 & 32,9 & 32,8 & 33,0 & 32,4 & 33,7 & 35,3 \\
\hline Belgium & 7,9 & 7,8 & 7,9 & 8,0 & 7,9 & 8,0 & 7,8 & 9,0 & 8,5 \\
\hline Bulgaria & 19 & 18,8 & 19,0 & 19,2 & 19,1 & 19,2 & 18,9 & 20,1 & 20,6 \\
\hline Cyprus & 8,1 & 8,0 & 8,1 & 8,2 & 8,1 & 8,2 & 8,0 & 9,2 & 8,8 \\
\hline Czech & 12 & & & & & & & & \\
\hline Republic & $\begin{array}{r}4 \\
27\end{array}$ & 12,3 & 12,4 & 12,5 & 2,5 & 12,6 & 12,3 & 13,5 & 13,4 \\
\hline Denmark & $\begin{array}{r}2 \\
25\end{array}$ & 27,0 & 27,1 & 27,4 & 27,4 & 27,5 & 27,0 & 28,3 & 29,4 \\
\hline Estonia & $\begin{array}{c}6 \\
36\end{array}$ & 25,4 & 25,5 & 25,8 & 25,8 & 25,9 & 25,4 & 26,7 & 27,7 \\
\hline Finland & $\begin{array}{r}8 \\
14,\end{array}$ & 36,5 & 36,7 & 37,1 & 37,0 & 37,2 & 36,6 & 37,9 & 39,8 \\
\hline France & $\begin{array}{r}2 \\
12\end{array}$ & 14,1 & 14,2 & 14,3 & 14,3 & 14,4 & 14,1 & 15,3 & 15,4 \\
\hline Germany & 4 & 12,3 & 12,4 & 12,5 & 12,5 & 12,6 & 12,3 & 13,5 & 13,4 \\
\hline Greece & 15 & 14,9 & 15,0 & 15,1 & 15,1 & 15,2 & 14,9 & 16,1 & 16,2 \\
\hline Hungary & 9,8 & 9,7 & 9,8 & 9,9 & 9,9 & 9,9 & 9,7 & 10,9 & 10,6 \\
\hline Ireland & $\begin{array}{l}7,8 \\
16\end{array}$ & 7,7 & 7,8 & 7,9 & 7,8 & 7,9 & 7,7 & 8,9 & 8,4 \\
\hline Italy & $\begin{array}{r}7 \\
37\end{array}$ & 16,5 & 16,7 & 16,8 & 16,8 & 16,9 & 16,6 & 17,8 & 18,1 \\
\hline Latvia & 1 & 36,8 & 37,0 & 37,4 & 37,3 & 37,5 & 36,8 & 38,2 & 40,1 \\
\hline Lithuania & 23 & 22,8 & 22,9 & 23,2 & 23,1 & 23,3 & 22,8 & 24,1 & 24,9 \\
\hline Luxembourg & 3,6 & 3,6 & 3,6 & 3,6 & 3,6 & 3,6 & 3,6 & 4,7 & 3,9 \\
\hline Netherlands & 4,5 & 4,5 & 4,5 & 4,5 & 4,5 & 4,6 & 4,5 & 5,6 & 4,9 \\
\hline Poland & $\begin{array}{r}3 \\
25\end{array}$ & 11,2 & 11,3 & 11,4 & 11,4 & 11,4 & 11,2 & 12,4 & 12,2 \\
\hline Portugal & $\begin{array}{r}7 \\
23\end{array}$ & 25,5 & 25,6 & 25,9 & 25,9 & 26,0 & 25,5 & 26,8 & 27,8 \\
\hline Romania & 9 & 23,7 & 23,8 & 24,1 & 24,0 & 24,2 & 23,7 & 25,0 & 25,9 \\
\hline Slovakia & $\begin{array}{l}9,8 \\
21\end{array}$ & 9,7 & 9,8 & 9,9 & 9,9 & 9,9 & 9,7 & 10,9 & 10,6 \\
\hline Slovenia & $\begin{array}{r}5 \\
15\end{array}$ & 21,3 & 21,5 & 21,7 & 21,6 & 21,8 & 21,4 & 22,6 & 23,3 \\
\hline Spain & $\begin{array}{r}4 \\
52\end{array}$ & 15,3 & 15,4 & 15,5 & 15,5 & 15,6 & 15,3 & 16,5 & 16,7 \\
\hline $\begin{array}{l}\text { Sweden } \\
\text { United }\end{array}$ & 1 & 51,6 & 52,0 & 52,6 & 52,4 & 52,7 & 51,7 & 53,2 & 56,4 \\
\hline Kingdom & 5,1 & 5,1 & 5,1 & 5,1 & 5,1 & 5,2 & 5,1 & 6,2 & 5,5 \\
\hline
\end{tabular}




\section{HIGHLIGHTS}

- 1st empirical analysis of how political factors affect renewable energy deployment

- Lobbying by the manufacturing industry negatively affect RE deployment

- Better governance quality increase RE deployment

- Left-wing parties promote deployment of RE more than right wing ones.

- Political factors are a quantitatively important driver of RE deployment 